\title{
Mission to (16) Psyche
}

Polanskey, Carol ; Elkins-Tanton, Linda ; Bell, James ; Binzel, Richard; Lawrence, David ; Merayo, José; Park, Ryan; Weiss, Benjamin ; Williams, David

\section{Published in:}

EPSC Abstracts

Link to article, DOI:

10.5194/epsc2020-988

Publication date:

2020

Document Version

Publisher's PDF, also known as Version of record

Link back to DTU Orbit

Citation $(A P A)$ :

Polanskey, C., Elkins-Tanton, L., Bell, J., Binzel, R., Lawrence, D., Merayo, J., Park, R., Weiss, B., \& Williams, D. (2020). Mission to (16) Psyche. In EPSC Abstracts (Vol. 14). [EPSC2020-988] Europlanet Society. https://doi.org/10.5194/epsc2020-988

\section{General rights}

Copyright and moral rights for the publications made accessible in the public portal are retained by the authors and/or other copyright owners and it is a condition of accessing publications that users recognise and abide by the legal requirements associated with these rights.

- Users may download and print one copy of any publication from the public portal for the purpose of private study or research.

- You may not further distribute the material or use it for any profit-making activity or commercial gain

- You may freely distribute the URL identifying the publication in the public portal

If you believe that this document breaches copyright please contact us providing details, and we will remove access to the work immediately and investigate your claim 
EPSC Abstracts

Vol. 14, EPSC2020-988, 2020, updated on 04 Mar 2021

https://doi.org/10.5194/epsc2020-988

Europlanet Science Congress 2020

(C) Author(s) 2021. This work is distributed under

the Creative Commons Attribution 4.0 License.

\section{Mission to (16) Psyche}

Carol Polanskey ${ }^{1}$, Linda Elkins-Tanton ${ }^{2}$, James Bell ${ }^{2}$, Richard Binzel ${ }^{3}$, David Lawrence ${ }^{4}$, Jose Merayo $^{5}$, Ryan Park ${ }^{1}$, Benjamin Weiss ${ }^{3}$, and David Williams ${ }^{2}$

${ }^{1}$ Jet Propulsion Laboratory, California Institute of Technology, United States of America (carol.polanskey@jpl.nasa.gov)

${ }^{2}$ Arizona State University, Tempe, AZ, USA

${ }^{3}$ Massachusetts Institute of Technology, Cambridge, MA, USA

${ }^{4}$ Johns Hopkins Applied Physics Laboratory, Laurel, MD, USA

${ }^{5}$ Technical University of Denmark, Lyngby, Denmark

\section{Introduction}

The Psyche mission began development in January 2017 when it was selected by NASA as the $14^{\text {th }}$ Discovery Class mission. Having successfully completed its critical design review, the spacecraft is being assembled by MAXAR and the Jet Propulsion Laboratory under the leadership of the PI, Linda Elkins-Tanton, at Arizona State University. The mission plans to explore for the first time the mainbelt asteroid (16) Psyche. Launch is planned for August 2022 leading to rendezvous with Psyche in early 2026.

Early radar [1] and spectroscopic measurements [2] of Psyche indicated a metallic composition leading to speculation that Psyche was the remnant core of a larger differentiated asteroid. Continued observing over decades has resulted in varying estimates for key physical parameters. Current expectations are that Psyche is a mix of rock and metal and that a complete understanding of its composition and origin awaits closer inspection by the Psyche science instruments [3]. The mission concept is designed to distinguish between the range of possible compositions. The science objectives of the Psyche mission are to:

1. Determine whether Psyche is a core, or if it is unmelted material.

2. Determine the relative ages of regions of its surface.

3. Determine whether small metal bodies incorporate the same light elements as are expected in the Earth's high-pressure core.

4. Determine whether Psyche was formed under conditions more oxidizing or more reducing than Earth's core.

5. Characterize Psyche's topography.

\section{Mission Overview}

The Psyche mission operations concept is inherited from the Dawn mission to Vesta and Ceres. The Psyche spacecraft will orbit the asteroid at a series of four progressively lower orbits (Orbits A-D) 
that provide increasingly higher resolution science measurements. Each orbit phase is designed to address specific science objectives and provide refinements to Psyche's shape and mass that enable the descent to the next orbit. Like Dawn, the Psyche mission uses solar electric propulsion to travel to Psyche as well as enter orbit and transfer between the science orbits. Figure 1 shows the spacecraft interplanetary trajectory and key mission dates.

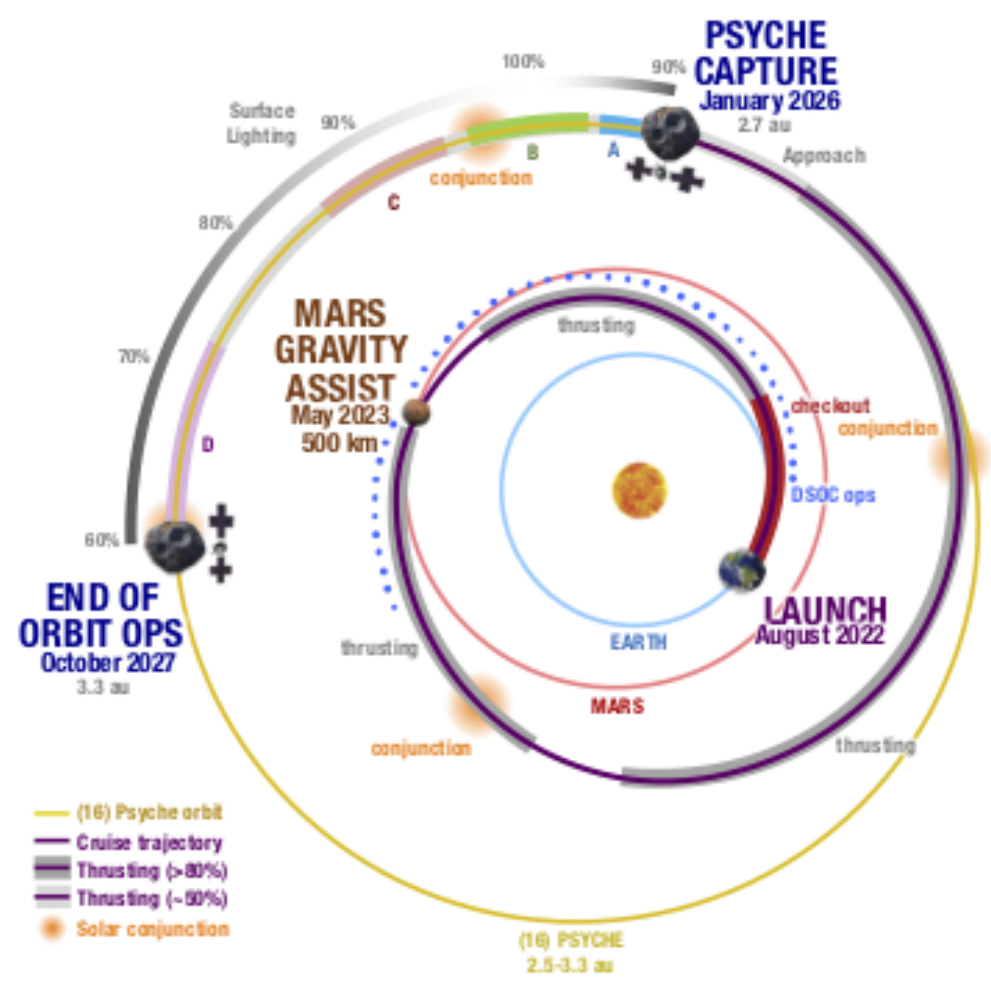

Figure 1: Interplanetary trajectory of the Psyche spacecraft.

\section{Science Investigations}

The Psyche spacecraft plans to carry three science instruments and conduct the gravity science investigation using the $\mathrm{X}$-band telecommunication system.

The magnetometer consists of two sensors mounted on a 2-m boom in a gradiometer configuration. The instrument is developed by the Technical University of Denmark with heritage from SWARM [4] whereas the science investigation is managed at the Massachusetts Institute of Technology. Figure 2 shows the magnetometer sensors and electronics units. The primary objective of the magnetometer is to search for the existence of a remanent magnetic field that would confirm that Psyche was once a planetary core. The magnetometer is operated continuously starting shortly after launch until the end of the mission with its science objectives achieved in Orbit C. 


\section{Magnetometer}
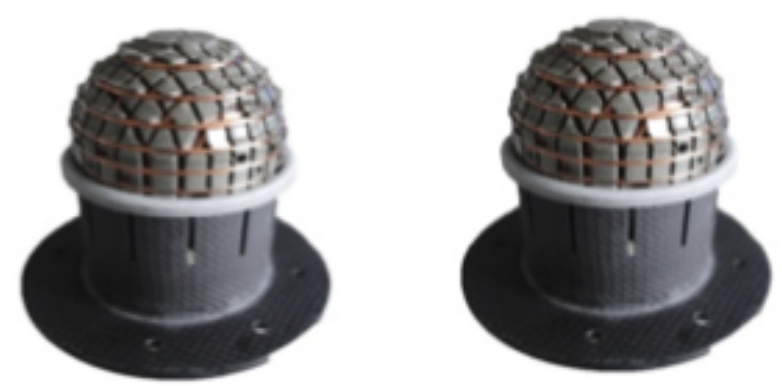

2 Magnetometer Sensors
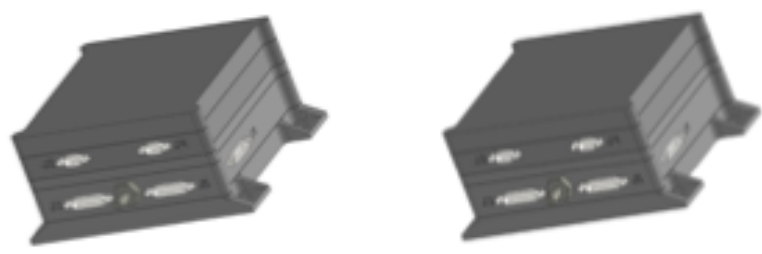

\section{Electronics Units}

Figure 2: Psyche magnetometer.

The multispectral imager consists of two redundant imagers with a panchromatic and seven narrowband filters. The filters were selected to detect minerals such as oldhamite, olivine, and pyroxene that would help discriminate between Psyche formation scenarios. The imaging campaign also provides the Psyche shape model and data to make a geologic map. Figure 3 shows the imager hardware being developed by Malin Space Science Systems that is managed and operated by Arizona State University with heritage from MSL MastCam and MCO MARCI [5]. Orbits A and B are the primary science orbits for the imager providing global maps up to $20 \mathrm{~m} /$ pixel. Imaging will also continue throughout the remainder of the mission. 


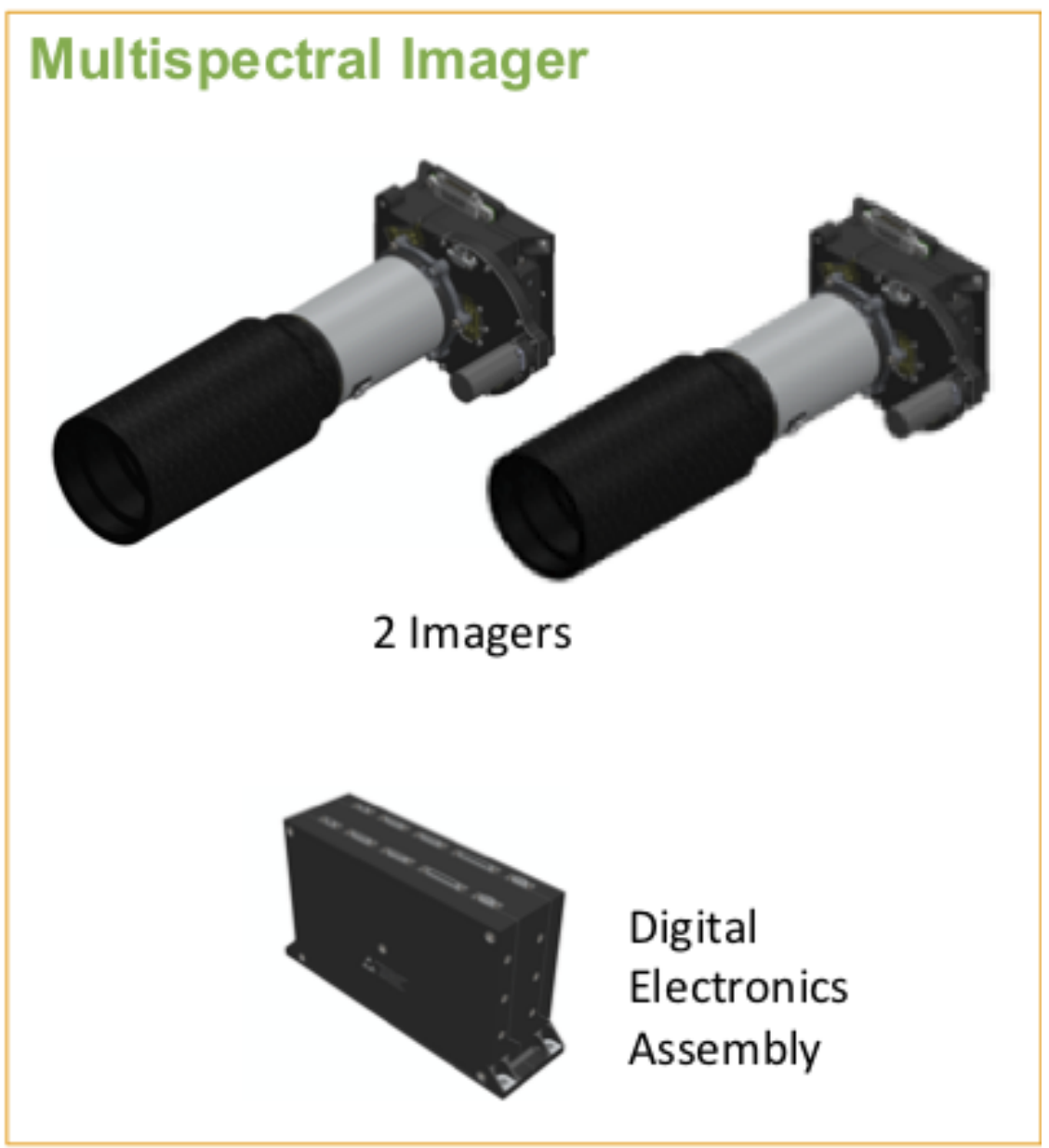

Figure 3: Psyche multispectral imager.

The gamma-ray and neutron spectrometer (GRNS) consists of two separate units mounted on their own 2-m boom (Fig 4). GRNS is developed by the Johns Hopkins Applied Physics Laboratory with heritage from MESSENGER and Lunar Prospector [6]. The GRNS provides elemental composition measurements for key elements such as nickel, iron, sulfur, silicon, potassium, and others. Nickel content is an indicator of whether Psyche is a remnant core or unmelted material. GRNS will be able to map the distribution of metals and silicates across the surface and measure nickel content to 2 $w t \%$ in Orbit D. 


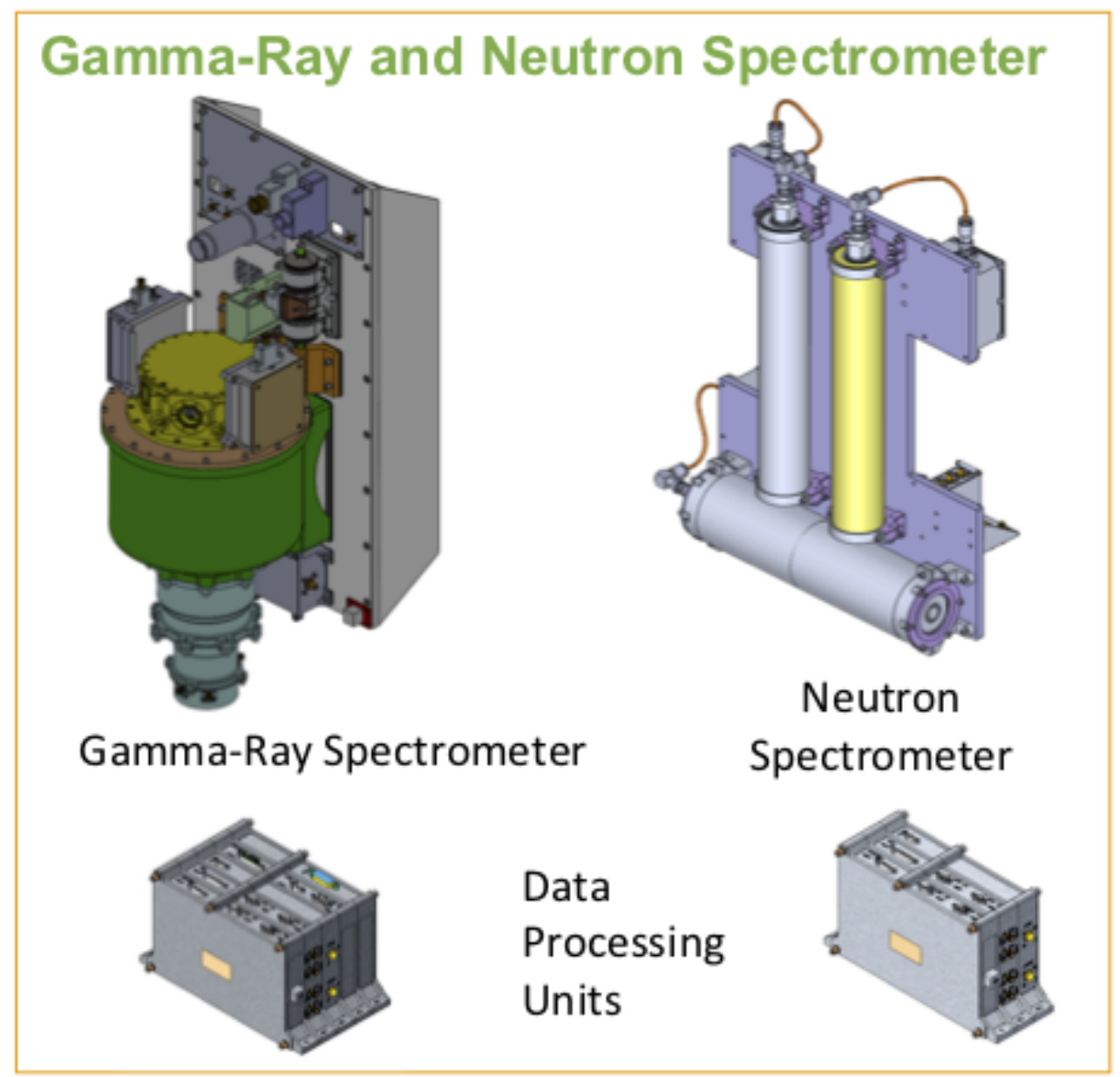

Figure 4: Psyche GRNS.

The X-band telecommunication system is capable of providing two-way coherent Doppler and ranging data via Deep Space Network (DSN) tracking that will be used to map the gravity field of Psyche and to probe its interior structure.

The Deep Space Optical Communications (DSOC) technology demonstration is planned as part of the mission payload. It does not play a role in the science investigations.

\section{Summary}

The Psyche mission development is proceeding on schedule. Meanwhile, the Psyche asteroid is becoming a more complex and compelling target.

\section{Acknowledgements}

This work was, in part, carried out at the Jet Propulsion Laboratory, California Institute of Technology, under contract with the National Aeronautics and Space Administration.

\section{References}

[1] Ostro, S. J. et al. (1985) Science, 229, 442-446.

[2] Binzel, et al. (1995) Icarus, 117, 443-445.

[3] Elkins-Tanton, L. T. et al. (2020) JGR Planets, 125, doi: 10.1029/2019JE006296. 
[4] Merayo, J.M. et al. (2008), In: Small Satellites for Earth Observation, Springer, Dordrecht, doi: 10.1007/978-1-4020-6943-7_13.

[5] Bell, J. F. et al. (2016) LPSC XLVII.

[6] Lawrence, D. J. et al. (2019) LPSC L. 